\title{
Pediatric visceral leishmaniasis in Tartous, Syria
}

\author{
Ali Othman Hamwi, Ali Abdallatif Mohammad, Sara Othman Hamwi, Razan Abdallatif Mohammad, Kayss Younis Shahin² \\ College of Medicine, University of Tartous, Tartous, ${ }^{1}$ Department of Rheumatology, Tishreen Hospital, Latakia, ${ }^{2}$ Department of Paediatrics and \\ Haematology, Tartous Children's Hospital, Tartous, Syrian Arab Republic
}

\begin{tabular}{|c|}
\hline Access this article online \\
\hline Website: www.avicennajmed.com \\
\hline DOI: 10.4103/ajm.ajm_168_20 \\
\hline Quick Response Code: \\
\hline \\
\hline
\end{tabular}

\section{ABSTRACT}

Background: Visceral leishmaniasis (VL) type in Syria is Lashmania infantum, a fatal incapacitating disease, which is mostly seen in infants. Subjects and Methods: Hospital records of 19 children with VL were retrospectively reviewed. The period of the study was from June 2016 to July 2019. Results: The median age of the patients was 45.5 months. None was coinfected with human immunodeficiency virus or known to be immunocompromised. Pallor and anemia were observed in all cases, fever in $13(68.42 \%)$, splenomegaly in $18(94.7 \%)$, hepatomegaly in 11 (57.9\%), thrombocytopenia in 15 (78.95\%), and leukopenia in nine (47.4\%). A bone marrow aspirate was obtained and Leishmania amastigotes were detected in all patients. All patients were initially treated with meglumine antimonate; one child did not respond and was treated with lipid formulations of amphotericin B. Conclusions: Presentation of VL in the pediatric age group is characterized by pallor, fever, splenomegaly, and hepatomegaly. Hematological and biochemical indices are typical with cytopenias. In all cases, microscopic examination provided a positive diagnosis. Despite recent reports on decreased responses to antimonial drugs of patients with Mediterranean VL, meglumine antimonate treatment appears to be still highly effective in Syria.

Key words: Children, Leishmania infantum, meglumine antimonate, pediatric, visceral leishmaniasis

\section{INTRODUCTION}

Leishmaniasis consists of a complex of vector-borne diseases caused by more than 20 species of the protozoan genus Leishmania and is transmitted by sand fly vectors. Visceral leishmaniasis (VL) is caused primarily by the two related species Lashmania donovani and L. infantum (synonym L. chagasi). ${ }^{[1]}$

Lashmania infantum occurs in the Mediterranean (including Spain, France, and Greece), the Middle East, Afghanistan, Iran, Pakistan, and Brazil. In addition, sporadic cases have been reported in Central Asia, China, Mexico, and Central and Latin America outside of Brazil. ${ }^{[2]}$

We present the epidemiological, clinical, hematological, biochemical, and therapeutic characteristics of VL in 19

Address for correspondence: Mr. Ali Othman Hamwi

College of Medicine, University of Tartous, Safita,

Tartous, Syrian Arab Republic.

E-mail: AliOthmanHamwi@tartous-univ.edu.sy children, who were admitted to Children's Hospital, between 2016 and 2019.

\section{SUBJECTS AND METHODS}

The details recorded included the patient and family history, area of residence, physical examination, ultrasonography, and laboratory tests included complete blood count, erythrocyte sedimentation rate (ESR), C-reactive protein (CRP) level, Widal test and Wright test to exclude the typhoid fever, and Brucellosis, respectively. Polymerase chain reactions (PCRs) were carried out in two patients

This is an open access journal, and articles are distributed under the terms of the Creative Commons Attribution-NonCommercial-ShareAlike 4.0 License, which allows others to remix, tweak, and build upon the work non-commercially, as long as appropriate credit is given and the new creations are licensed under the identical terms.

For reprints contact: reprints@medknow.com

Cite this article as: Hamwi AO, Mohammad AA, Hamwi SO, Mohammad RA, Shahin KY. Pediatric visceral leishmaniasis in Tartous, Syria. Avicenna J Med 2020;10:223-6. 
to avoid the risks of bone marrow aspiration such as tibial plateau displacement. Diagnosis of VL was established according to the following criteria: (1) clinical picture, (2) laboratory tests, and (3) demonstration of Leishmania parasites in Giemsa-stained bone marrow aspirates.

Bone marrow aspirates were obtained from patients for direct examination by microscopy after staining with Giemsa.

Patients were treated with meglumine antimonate (Glucantim) and liposomal amphotericin B.

Meglumine antimonate was administered intramuscular for 28 days at a dosage of $20 \mathrm{mg} / \mathrm{kg} /$ day.

Liposomal amphotericin B was administered intravenus at a dosage of $3 \mathrm{mg} / \mathrm{kg}$ on days $1,2,3,4,5,10$, and 21 to the patients who did not respond to the antimonial treatment.

Clinical response was assessed after treatment and was defined as cure (defervescence, normalization of laboratory results, and reduction of spleen and liver size) or failure (persistence of clinical and laboratory findings).

\section{RESULTS}

The patients' age ranged from 10 months to 13 years. All of the patients were human immunodeficiency virus-negative and not immunosuppressed. The cases are listed with the categories of age, sex, local origin, symptoms, clinical findings methods of diagnosis used, and treatment in Table 1. Hematological and biochemical data of the patients are given in Table 2.
The symptoms of the patients began 5-77 days before diagnosis (median $=29.5, \mathrm{SD}=18.74)$. Two patients had a concurrent urinary tract infection. Hypersplenism was observed in two patients and they had a transfusion. Detection of Leishmania antibodies by the (PCR) antibody test had been carried out in two patients, one of them had a positive result and the other had a negative one. Only one patient needed an additional course of treatment with Glucantim for 15 days without any improvements therefore the treatment was switched to liposomal amphotericin B. No adverse effects were reported. No splenectomy was performed. All children were recovered.

\section{DISCUSSION}

In Syria, two types of Leishmaniasis are observed: L. infantum is responsible for infantile Mediterranean VL, whereas L. tropica causes cutaneous leishmaniasis (CL) ${ }^{[3,4]}$

Until 1960 cutaneous leishmaniasis prevalence in Syria was restricted to two areas to which it is endemic (Aleppo and Damascus). ${ }^{[5]}$ However, in early 2013 41,000 cutaneous leishmaniasis were reported. ${ }^{[5,6]}$

Our data showed that there was an increase in VL cases in Syria. ${ }^{[7,8]}$ In our study of VL, the cases originated in north, east, south Tartous due to the randomized population expanding in the last 10 years which increased the contiguity between humans and wild animals which is considered a natural reservoir of leishmaniasis such as dogs and jackals.

The clinical manifestations of VL in Syria suggest that it is the Mediterranean type, which is mostly seen in pediatric age. ${ }^{[9]}$ Presentation of VL in this age group is characterized

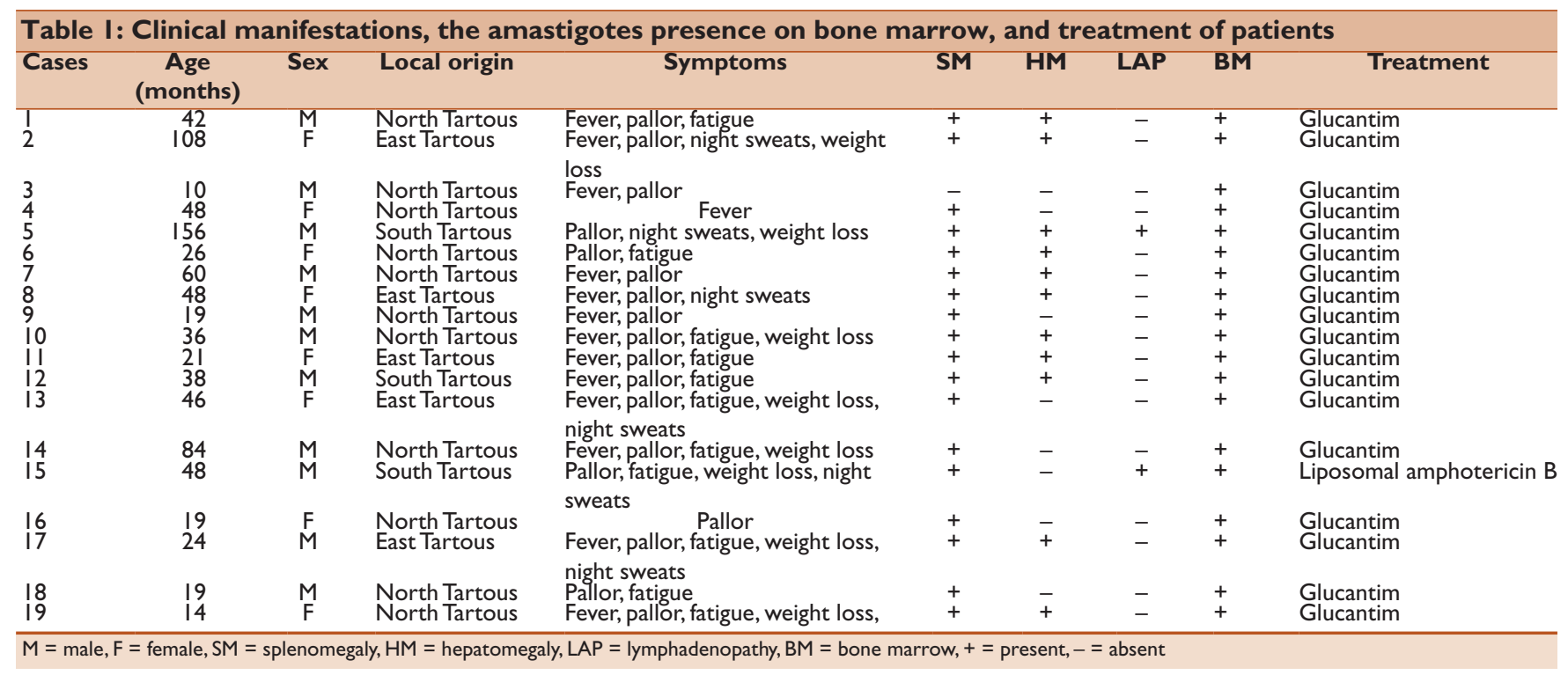




\begin{tabular}{|c|c|c|c|c|c|c|c|c|c|}
\hline Cases & $\begin{array}{c}\text { RBC } \\
\left(\times 10^{6} / \mu L\right)\end{array}$ & $\mathrm{Hb}(\mathrm{g} / \mathrm{dl})$ & Hct \% & $\begin{array}{c}\text { WBC } \\
\left(x \mid 0^{3} / \mu L\right)\end{array}$ & $\begin{array}{l}\text { Platelet } \\
\left(x \mid 0^{3} / \mu L\right)\end{array}$ & ESR $(\mathrm{mm} / \mathrm{h})$ & CRP (mg/l) & Widal test & Wright test \\
\hline I & 3.7 & 6.1 & 19.7 & 3.7 & 80 & & 95.5 & - & - \\
\hline 2 & 5.36 & 11.4 & 34.7 & 4.19 & 250 & & & - & - \\
\hline 3 & 3.1 & 5.8 & 19 & 4 & 29 & & 132 & - & - \\
\hline 4 & 3.38 & 8.4 & 25.6 & 5.4 & 109 & & 101 & - & - \\
\hline 5 & 3.99 & 8.4 & 29.4 & 4.1 & 137 & & 29.5 & - & - \\
\hline 6 & 2.25 & 5.1 & 14.8 & 3.1 & II & & & - & - \\
\hline 7 & 3.45 & 9.5 & 27.6 & 10.8 & 448 & & 0.1 & - & - \\
\hline 8 & 2.85 & 7.8 & 23 & 4.7 & 200 & 92 & 45.9 & - & - \\
\hline 9 & 2.8 & 5.2 & 17 & 3.2 & 75 & 85 & 112 & - & - \\
\hline 10 & 4.72 & 11.5 & 33.3 & 3.52 & 53 & 98 & 37.3 & - & - \\
\hline 11 & 2.3 & 4.7 & 15 & 4.9 & 39 & & & - & - \\
\hline 12 & $3.4 I$ & 8 & 25 & 2.3 & 100 & 51 & 52 & + & - \\
\hline 13 & 3.78 & 8.6 & 27 & 3.6 & 73 & 120 & 148 & - & - \\
\hline 14 & 5.8 & 8.5 & 28.5 & 2.9 & 226 & 78 & 107 & - & - \\
\hline 15 & 3.5 & 5.4 & 17 & 6.2 & 134 & 90 & 102.4 & - & - \\
\hline 16 & 3.19 & 5.9 & 18.5 & 4.1 & 77 & & 2.6 & - & - \\
\hline 17 & 2.75 & 5.8 & 18 & 3.3 & 78 & & & - & - \\
\hline 18 & 2.2 & 5 & 16 & 2.9 & 26 & & & - & - \\
\hline 19 & 2.65 & 5.3 & 20 & 4.2 & 49 & 140 & 138.3 & - & - \\
\hline
\end{tabular}

by pallor, fever, splenomegaly, and hepatomegaly. ${ }^{[7-9]}$ These features were observed in the majority of the present infants. None of the current patients presented with dermal aspects such as hyperpigmentation, which is typical of the disease acquired in countries other than India and Bangladesh. ${ }^{[10,11]}$

No therapeutic complications were reported. Hematological and biochemical indices are typical with cytopenias and increased ESR, ${ }^{[7-9]}$ all of the patients had anemia, 78.95\% of them had thrombocytopenia, $47.46 \%$ had leukopenia, and 13 patients out of 14 had increased CRP levels. These hematological abnormalities, observed in this study, are similar to the data reported by other workers. ${ }^{[7-9]}$

Examination of bone marrow smears was positive in $100 \%$ of present cases. Thirty-six point $84 \%$ of the patients were initially misdiagnosed. The clinical picture of VL may also be the same as that of malaria, typhoid fever, miliary tuberculosis, brucellosis, syphilis, amoebic liver abscess, infectious mononucleosis, lymphoma, and leukemia. ${ }^{[12,13]}$

Leukopenia is predisposing factor to development of secondary infections in patients with VL. ${ }^{[14]}$ We also observed that two patients experienced urinary tract infection which presented with fever $\left(>39^{\circ} \mathrm{C}\right)$, poor feeding, vomiting, and irritability more than 2 days. ${ }^{[15]}$ The treatment included IV fluid replacement and parenteral antibiotics (cephalosporin, amoxicillin-clavulanic, acid, and trimethoprim-sulfametoxazole). ${ }^{[16]}$

The main treatment used in Syria is meglumine antimonate. ${ }^{[17]}$
Another study from Turkey reported that of 40 patients treated with meglumine antimonate, 38 responded well without significant side effects. ${ }^{[18]}$

All of the present patients were treated initially with meglumine antimonate. One child, whose condition did not improve with two courses of meglumine antimonate, recovered when treated with liposomal amphotericin- $\mathrm{B}^{[19]}$

Our results show that treatment of VL with antimonials in pediatric patients is a relatively inexpensive, safe, and effective treatment, as reported by other authors. ${ }^{[18]}$

\section{Financial support and sponsorship}

Nil.

\section{Conflicts of interest}

There are no conflicts of interest.

\section{REFERENCES}

1. Diagnosis and Treatment of Leishmaniasis. Clinical Practice Guidelines by the Infectious Diseases Society of America (IDSA) and the American Society of Tropical Medicine and Hygiene (ASTMH); 2016. Available from: http://cid.oxfordjournals.org/content/early/2016/11/03/cid. ciw670.full.pdf + html. [Last accessed on 2016 Nov 16].

2. WHO/Department of Control of Neglected Tropical Diseases. Global leishmaniasis update, 2006-2015: A turning point in leishmaniasis surveillance. Wkly Epidemiol Rec 2017;92:557.

3. Pratlong F, Lami P, Ravel C, Balard Y, Dereure J, Serres G, et al. Geographical distribution and epidemiological features of old world leishmania infantum and leishmania donovani foci, based on the isoenzyme analysis of 2277 strains. Parasitology 2013;140:423-34.

4. Mniouil M, Fellah H, Amarir F, Et-touys A, Bekhti Kh, Adlaoui El B, et al. Epidemiological characteristics of visceral leishmaniasis in Morocco (1990-2014): An update. Acta Tropica 2017;170:169-77. 
5. Hayani K, Dandashli A, Weisshaar E. Cutaneous leishmaniasis in Syria clinical features, current status and the effects of war. Acta Derm Venereol 2015;96:62-6.

6. Haddad N, Saliba H, Altawil A, Villinsky J, Al-Nahhas S. Cutaneous leishmaniasis in the central provinces of Hama and edlib in Syria: Vector identification and parasite typing. Parasit Vectors 2015;8:524.

7. Youssef A, Harfouch R, El Zein S, Alshehabi Z, Shaaban R, Kanj S. Visceral and cutaneous leishmaniasis in a city in Syria and the effects of the Syrian conflict. Amj J Trop Med Hyg 2019;101:108-12.

8. El Hajj R, El Hajj H, Khalifeh I. Fatal visceral leishmaniasis caused by leishmania infantum, Lebanon. Emerg Infect Dis 2018;24:906-7.

9. Petrela R, Kuneshka L, Foto E, Zavalani F, Gradoni L. Pediatric visceral leishmaniasis in Albania: A retrospective analysis of 1,210 consecutive hospitalized patients (1995-2009). PLoS Negl Trop Dis 2010;4:e814.

10. Magill A. Leishmania species. Chapter 277. In: Bennett JE, Dolin R, Blaser MJ, editors. Principles and Practice of Infectious Diseases. 8th ed. Philadelphia, PA: Elsevier; 2015. p. 3091-107.

11. Jeronimo S, de Queiroz Sousa A, Pearson R. Leishmaniasis. In: Guerrant RL, Walker DH, Peter F, editors. Tropical Infectious Diseases: Principles, Pathogens, and Practice. 2nd ed. Philadelphia, PA: Saunders Publishing; 2006. p. 1095-113.

12. Stark CG. Leishmaniasis; February 18, 2020. Available from: https:// emedicine.medscape.com/article/220298-overview?src = android\&de vicetype $=$ android $\&$ osversion $=9 \&$ appversion $=6.1 .1 \& s r c=$ medscape app-android\&ref=share. [Last accessed on $2020 \mathrm{Apr} 14$ ].
13. Berhe N, Hailu A, Abraham Y, Tadesse Y, Breivik K, Abebe Y. Intercurrent and nosocomial infections among visceral leishmaniasis patients in ethiopia: An observational study. Acta Trop 2001;80: 87-95.

14. World Health Organization. Leishmaniasis in Syrian Arab Republic. 2016. [cited 2018 Mar 4]. Available from: http://www.who.int/ leishmaniasis/resources/Leishmaniasis_cp_Syria_2014_updated.pdf. [Last accessed on 2020 May 5].

15. Shaikh $\mathrm{N}$, Hoberman A. Urinary tract infections in infants and children older than one month: Clinical features and diagnosis. 2020. Available from: https://www.uptodate.com/contents/urinary-tractinfectionsin-infants-and-children-older-than-one-month-clinicalfeatures-anddiagnosis. [Last accessed on 2020 May 8].

16. Bloomfield P, Hodson EM, Craig JC. Antibiotics for acute pyelonephritis in children. Cochrane Database Syst Rev Jan 25 2005;(1):CD003772.

17. Totan M, Dagdemir A, Muslu A, Albayrak D. Visceral childhood leishmaniasis in turkey. Acta Paediatr 2002;91:62-4.

18. Das VN, Siddiqui NA, Pandey K, Singh VP, Topno RK, Singh D, et al. A controlled, randomized nonblinded clinical trial to assess the efficacy of amphotericin B deoxycholate as compared to pentamidine for the treatment of antimony unresponsive visceral leishmaniasis cases in Bihar, India. Ther Clin Risk Manag 2009;5:117-24.

19. Grech V, Mizzi J, Mangion M, Vella C. Visceral leishmaniasis in Malta: An 18 year paediatric, population based study. Arch Dis Child 2000;82:381-5. 